\title{
Afbeeldinge van Christus. Die toepasbaarheid van die leer van die an- en enhupostase om die tweede gebod op Christus van toepassing te maak.
}

DJ SMITH

Die vraag of daar wel afbeeldinge van Christus gemaak kan word, soos byvoorbeeld in die sg. kinderbybels, is ' $n$ vraag wat nie in alle kerklike groeperinge as problematies ervaar word nie. So sal ' $n$ Rooms-Katoliek geen probleem hê om die vraag bevestigend te antwoord nie. In die kerke van Calvinistiese oorsprong is dit egter heel anders gesteld. Die Calvinisme staan tradisioneel afwysend teenoor enige afbeeldinge van Christus. Hierdie afwysende houding kan in 'n groot mate toegeskryf word aan die feit dat die Calvinisme van die begin af alle klem op die Woord alleen gelê het, die Woord as enigste bron van openbaring vir die kerk. Haitjema $(4, p 237)$ het die stelling gemaak: "In het gereformeerd protestantisme waar alles hangt aan het Woord alleen, moet wel de uiterste ingetogenheid betracht worden tegen de beeldrijkheid van symbolische vormen in de liturgie, waarbij zo gemakkelijk "vooruitgegrepen" wordt op wat in eschatologische spanning als geloofswaarheid de distantie tussen de God des heils en zijn schepsel zal moeten blijven eerbiedigen". Hierdie stelling kan net so van toepassing gemaak word op die Calvinisme se houding ten opsigte van godsdienstige afbeeldinge in die algemeen en meer in die besonder dan ook van afbeeldinge van Christus.

Dit is aan die ander kant ook duidelik dat hierdie tradisionele siening in ons tyd nie meer eenstemmig deur almal in reformatoriese kring gedeel word nie. 'n Toenemende aantal geïllustreerde "kinderbybels" - ook met afbeeldinge van Christus - wat deur lidmate uit hierdie kring geskryf word, asook menings in privaatgesprek uitgespreek of neergepen soos onder ander deur Herman Scholtemeijer (10,p 9-11). 'n Nadere studie van die saak bring 'n mens tot die oortuiging dat dit nie ' $n$ vraag is wat sommer maklik 
met 'n eenvoudige ja of nee beantwoord kan word nie omdat hieragter 'n diep teologiese problematiek lê. Op hierdie teologiese problematiek sal ons later ingaan. Vir eers wil ons net kortliks die argumente wat contra en pro aangevoer word, aanstip.

Die standpunt teen afbeeldinge van Christus berus hoofsaaklik op die volgende argumente:

1. Die Skrif gee nêrens 'n voorstelling van hoe Christus na die liggaam gelyk het nie. Al waardeur Jesus geken kan word is deur sy woorde en werke, en die beeld van Jesus wat ons kan leer ken, kan ons alleen uit die Bybel leer ken. Daarby is dit opmerklik dat geen enkele tradisionele en egte afbeelding of portret van Jesus aan ons oorgelewer is nie (10,p 52 en $53 ; 2, p$ 9-11). Onses insiens word die krag van hierdie argument deur twee dinge verswak. Die eerste is dat 'n argumentum e silencio ' $n$ redelik belangrike rol speel. Die tweede is dat Jesus in 'n tyd geleef het toe die kamera nog nie ontdek is nie en die kuns van portretskildery wat die gewone man betref eintlik glad nie ter sprake was nie. Wat wel waar is in die argument is dat ons Christus as ons Verlosser alleen uit die Bybel kan leer ken.

2. ' $n$ Verdere argument is dat geen menslike voorstelling reg kan laat geskied aan die heerlikheid van Christus nie (12,p 53; 2,p 10). Hierteenoor sou wel opgemerk kon word dat die Christus waarom dit in afbeeldinge gaan, Christus na sy mensheid is.

3. Dit word ook gestel dat beelde en voorstellings maklik tot verswakking van die verkondiging kan lei (12,p 53). Dit is 'n argument wat alreeds in die tyd van die Hervorming deur die Reformatore baie skerp gestel is. Dit is beslis 'n geldige argument wat ons waarsku teen 'n immer teenwoordige gevaar vir die kerk.

4. Samehangend met bogenoemde argument word ook gestel dat die gevaar van beeldaanbidding versterk word. $\mathrm{Al}$ leef ons vandag in ' $n$ heel ander godsdienstige klimaat as in die tyd van die Hervorming, is dit waar dat ons steeds op hierdie gevaar bedag moet wees.

5. Die mees diepgaande beswaar teen die gebruik van afbeeldinge van Christus word vanuit die tweede gebod gemaak. So redeneer B] Engelbrecht dat ons die tweede gebod ook op Christus van toepassing moet maak en dat dit gedoen kan word omdat aanvaar word dat die volgende stelling van Christus geld: "die Seun het wel mens geword, maar het altyd tegelykertyd ewige, waaragtige God gebly. Nooit was Hy net mens nie. Hy was altyd God-mens 
wat prinsipieel onafbeeldbaar is" (5,p 1). Die saak word ook verder so begrond: "Trouens: Jesus was volgens die algemene ortodokse leer, nooit ' $n$ menslike persoon nie! Hy die ewige Seun het net ' $n$ menslike natuur aangeneem en dit saam met sy Goddelike natuur in die ewige Goddelike Persoon van die Seun saamgevoeg. Sy opstanding het duidelik laat blyk dat Hy altyd Seun van God was (Rom 1:4)" (3,p 1). In laasgenoemde stelling figureer die kerklike leer van die an- en enhupostasie as 'n argument om die tweede gebod ook op Christus van toepassing te maak. Aangesien ek van mening is dat bogenoemde leer die spil is waarom die argumente teen afbeeldinge van Christus draai, sal ons verder aan breedvoeriger op die saak ingaan om te sien of ons wel hier met 'n geldige redenasie te doen het.

6. Aansluitend by bogenoemde argument word ook gestel dat die tweede gebod impliseer dat ons God nooit op 'n ander wyse mag dien as wat $\mathrm{Hy}$ in sy Woord beveel nie, deur middel van die Woord alleen. God wil alleen in woordgestalte soos bv. prediking, sakrament en gebed gedien word en nie deur afbeeldinge, ens, nie (3,p 1 en $2, \mathrm{p} 9)$.

Die argumente ten gunste van die toelaatbaarheid van afbeeldinge van Christus kan wel vanuit ' $n$ wye verskeidenheid van invalshoeke benader word, maar kom uiteindelik net op een saak neer. Hierdie saak is dat Jesus in sy omwandelinge op aarde werklike, egte mens was wat in alles gelyk was aan ander mense behalwe die sonde. In lyn met die Nederlandse Geloofsbelydenis artikel 18, word gestel dat Christus heeltemal aan die mens gelyk geword het deur werklik 'n ware menslike natuur met al die swakhede daarvan - uitgesonderd die sonde - aan te neem. Dit beteken ook aldus die Nederlandse Geloofsbelydenis dat Hy nie net alleen die menslike liggaam aangeneem het nie, maar ook ' $n$ ware menslike siel. In die lig hiervan word gestel dat dit 'n verkeerde gebruik van die tweede gebod is om dit ook op Christus van toepassing te maak. Die tweede gebod verbied nie dat afbeeldinge van Christus gemaak word nie, maar wel dat God afgebeeld word, of deur beelde gedien word of dat beelde as God vereer word. Selfs al sou teenstanders van afbeeldinge van Christus na die verheerlikte Christus heenwys dan geld dit ook nog dat Jesus nie net mens was nie, maar nog steeds (ook in sy verheerlikte staat in die hemel), mens is. Hoewel Jesus as God nie afgebeeld kan word nie, kan Jesus as egte mens en egte Jood wat op aarde geleef en gewerk het afgebeeld word. Die groot voorwaarde is net 
dat so ' $n$ afbeelding nie vir godsdienstige verering en aanbidding gebruik word nie. Herman Scholtemeijer (10,p 7-9) redeneer langs bogenoemde lyne. Dit is skynbaar ook die gedagtegang wat agter PW Marais se aanvaarding van afbeeldinge van Christus lê (7,p 55).

Uit die paar kort opmerkings oor die argumente contra en pro afbeeldinge van Christus is dit duidelik dat daar agter die eenvoudige vraag of afbeeldinge van Christus toelaatbaar is of nie, wel 'n diep teologiese problematiek lê. Die groot vraag wat in werklikheid agter alles lê, is die vraag wat Christelike teoloë van die begin af besig gehou het, $\mathrm{nl}$ die vraag wie Jesus werklik is; die vraag na die Persoon van Christus. Dit gaan om die vraag van hoe die verhouding tussen Godheid en mensheid in die Persoon van Christus verstaan word. Dit is ' $n$ vraag wat vanuit 'n spesifieke verstaan van die leer oor die twee nature van Christus verstaan word. Dit word veral by die standpunt teen afbeeldinge van Christus duidelik dat die argument gevoer word vanuit 'n standpunt wat sterk gevorm is deur die oud-kerklike leer van die anhupostasie en enhupostasie van Christus of dan in elk geval 'n standpunt wat onbewustelik sterk aansluit by hierdie leer. Só is dit in elk geval met die reeds aangehaalde standpunt van BJ Engelbrecht as hy sê: "Trouens, Jesus was volgens algemene ortodokse leer, nooit 'n menslike persoon nie! ..." $(3,1)$.

Dit is vir die verdere gang van ons redenasie nodig dat ons enkele opmerkings sal maak oor die leer van die anhupostasie en enhupostasie. Hierdie leer het sy oorsprong by die vyfde ekumeniese konsilie wat in 553 in Konstantinopel vergader het, om 'n verdere verklaring van die uitsprake van die konsilie van Chalcedon oor die twee nature van Christus te gee. Hierdie konsilie was die gevolg van 'n versoeningspoging met die Monofisiete, hoewel die Monofisitisme self steeds afgewys is. Die Monofisiete het dit baie sterk beklemtoon dat Christus as die Goddelike Logos wat vlees geword het, net een natuur gehad het. Hulle het hierdie klem so sterk gelê dat die menslike in Christus gedreig het om heeltemal in die goddelike opgelos te word. Die konsilie wou egter tegelykertyd ook die Nestorianisme afwys wat aan die ander kant gesê het dat die egtheid van Christus se twee nature alleen gehandhaaf kan word deur te aanvaar dat daar in Christus twee onderskeie persone was: die Goddelike en die menslike. Hulle eenheid sou dan net daarin lê dat hulle met mekaar in gemeenskap verkeer het. Hiér het weer 'n volledige skeiding van die nature van Christus gedreig. 
Met sy formulering van die leer van die an- en enhupostasie het hierdie konsilie van 553 van die oortuiging uitgegaan dat die eenheid van die twee nature van Christus in sy Persoon geleë is, dit is dus 'n personale eenheid ofte wel 'n hupostatiese eenheid (hupostasis = persoon). Hierdie hupostatiese eenheid of dan ook: die eenheid wat in die persoon geleë is, moet so verstaan word dat dit 'n eenheid is wat lê in die Persoon van die Logos, in die Persoon van Christus se Godheid. Hierdie hupostatiese eenheid is aan die een kant duidelik gemaak met die begrip anhupostasis wat beteken dat Christus se menslike natuur geen eie persoon (hupostasis) gehad het in die een Persoon van Christus nie. Aan die ander kant is hierdie eenheid van Persoon ook duidelik gemaak met die begrip enhupostasis wat weer wil sê dat hoewel Christus se menslike natuur geen eie persoon gehad het nie, Christus se menslike natuur sy persoonwees in die persoon van die Logos, dws Christus se Goddelike natuur vind (6,p 25 ff veral p 34 en 35; 11,p 109-115 veral 113-115; 13,p 142-145; 9,p 91-97; 8,p 250 en 251).

In hierdie leer het ons myns insiens 'n gebalanseerde, nodige en belangrike formulering van die Christologiese belydenis. Ons twyfel egter of hierdie leer of 'n denkpatroon langs die lyne van hierdie leer sonder meer gebruik kan word om die tweede gebod ook op Christus (soos $\mathrm{Hy}$ as mens op aarde geleef het) van toepassing te maak en so alle afbeeldinge van Christus af te wys. Hoe dié redenasie verloop, het ons hierbo aangetoon by punt vyf van die argumente teen afbeeldinge van Christus.

Dit is belangrik om wanneer ons die leer van die an- en enhupostase gebruik, ons dit altyd sal interpreteer na die bedoeling van die oorspronklike opstellers daarvan. Hulle wou die Nestorianisme afwys, maar wou beslis ook nie die Monofisitisme aanvaar nie. Hoewel hierdie leer in terme geformuleer is wat aansluit by die monofisitiese terme het die kerklike beslissinge na die konsilie van Konstantinopel in 553 (soos bv in verband met die sg duoteletiese stryd) getoon dat ons nie so 'n uitleg kan gee waar Christus se menslike natuur dreig om met sy Goddelike natuur te versmelt nie. Ons sal altyd in gedagte hou dat die verwyt wel al dikwels uitgespreek is dat die kerk met die leer in die rigting van die Monofisitisme beweeg het en nie genoegsaam oog gehad het vir die gevare van die doketisme wat daarin skuil nie (soos aangestip by 6,p 35 ook 11,p 114).

Hierby moet ons ook in gedagte hou dat die leer van an- en 
enhupostase steeds voluit aansluit by die geloofsbelydenis van Chalcedon se beklemtoning van die egtheid van Christus se ware mensheid. Ons moet dus versigtig wees om nie 'n verklaring te gee waarin die egtheid van Christus se mensheid of van sy menslikaardse bestaan vervlugtig word nie.

Hierdie leer is 'n poging om die ware eenheid van God en mens in Christus te beklemtoon en onder woorde te bring, maar dan sonder om spekulatief-abstrak te probeer deurdring tot die Goddelike geheimenis van Christus se Persoon. G Rödding en LF Schultze (9,p 95 en 11,p 112) wys daarop dat die grootheid van geloofsbelydenis van Chalcedon (waarvan die leerstuk van die an- en enhupostasie 'n verdere verklaring wil wees) juis daarin lê dat dit nie probeer om die verhouding tussen samehorigheid van die twee nature van Christus in ' $n$ rasionele verklaring en in positiewe terme uiteen te sit nie, maar slegs in vier negatiewe uitsprake uiteen te sit hoe ons dit nie behoort te verstaan nie. Die Here word naamlik geken in twee nature wat onvermeng en onveranderd, onverdeeld en ongeskei in Hom aanwesig is. Ek glo dat ons in ons aanvaarding en gebruik van hierdie leerstuk van die an- en enhupostasie steeds hierdie eerbied vir die Goddelike geheimenis van die Persoon van Christus moet handhaaf.

In die gebruik van die leer van die an- en enhupostasie om die tweede gebod op Christus in sy menslike lewe en omwandeling op aarde van toepassing te maak, word daar na my oordeel aan die een kant te veel uitgegaan van ' $n$ abstrakte en spekulatief-neigende benadering. Aan die ander kant word daar ook gewerk met 'n rasionele verklaring van die verhouding tussen die mensheid en Godheid in Christus wat nie voldoende rekening hou met die grens wat die eerbied vir die Goddelike geheimenis van die Persoon van Christus aan ons stel nie.

Wanneer ons met die leer van die an- en enhupostasie werk, moet ons ook in gedagte hou dat dit geformuleer is met gebruikmaking van die filosofiese begrippe en filosofiese taal van daardie tyd. Hierdie taal en begrippe is nie meer direk en sonder verklaring vir ons toeganklik nie. So word daar byvoorbeeld 'n persoonsbegrip gebruik wat nie meer ooreenstem met wat ons vandag onder persoon verstaan nie (13,p 142). Om hierdie rede kan ons nie maar net hierdie leerstuk sondermeer gaan toepas nie, maar moet ons eers in ons moderne taal en begrippe die wesenlike saak wat in hierdie leerstuk tot uiting gebring word herformuleer. Dit is duidelik dat dit 
vir die opstellers van hierdie leerstuk nie daarom gegaan het om logies en fisies presies te verklaar hoe die geheimenis van Jesus se Persoon daar uitsien nie, maar dat dit veel eerder vir hulle daarom gegaan het dat Jesus se menslike natuur slegs in sy absolute oorgawe aan die Goddelike natuur reg begryp kan word en dat sy menslike natuur slegs sy waarde en betekenis het daarin dat dit deur sy Goddelike natuur "gedra word" (9,p 96). Hierdie saak waarom dit gaan word onses insiens redelik geslaagd in eietydse taal en begrippe geformuleer deur G Rödding (9,p 96 en 97) wanneer hy stel dat dit in hierdie leerstuk daarom gaan dat Christus as blote Persoon wat in die geskiedenis geleef het (as 'n mens soos ons) niks besonders is nie, op sigself eintlik geen betekenis het nie, maar dat die sin van sy aardse lewe daarin lê dat dit die lewe uit God verteenwoordig. Christus se aardse lewe moet verstaan word vanuit die lewe wat vanuit God kom. Dit wil sê die eintlike persoonvormende saak in Christus is die lewe wat uit God kom en hierdie lewe is ook die sin en begronding van sy aardse lewe. Die teologiese betekenis van Jesus van Nasaret wat in die geskiedenis geleef het, lê, aldus Rödding, daarin dat die lewe wat vanuit God kom, soos $\mathrm{Hy}$ dit verteenwoordig, die lewe van 'n werklike mens is.

Rödding formuleer hierdie saak miskien in te algemene terme, daarom is my mening dat dit beter is om te stel dat hierdie leerstuk vandag vir ons dit beteken: dat as ons Christus se mensheid en Godheid nie afsonderlik kan benader nie, maar dat Christus as mens en sy aardse bestaan alleen vir ons betekenis het omdat Hy God is wat as mens na ons toe gekom het. Ons kan in Christus as Verlosser glo omdat $\mathrm{Hy}$ nie maar net 'n unieke mens of voorbeeld van die volmaakte mens is nie maar omdat God in sy Persoon die leiding geneem het om ons van sonde en dood te verlos. Dit gaan in hierdie leerstuk in die positiewe sin van die woord om 'n hegemonie van die Goddelike in die Persoon van Christus (hierdie begrip is ontleen aan $\mathrm{H}$ Ott (8,p 250), maar in ietwat gewysigde sin), 'n hegemonie wat nie lei tot ' $n$ opname van die mensheid van Christus in Godheid nie, maar wat juis die volle waarde, plek en egtheid van Jesus se mensheid aan die lig bring.

In die lig van hierdie interpretasie wat ons hierbo voorgehou het, is dit ons oortuiging dat die enigste geldige interpretasie wat ons aan die leer van die an- en enhupostasie kan gee 'n interpretasie is wat aan die een kant vashou aan die uitspraak van die geloofsbelydenis van Chalcedon dat die onderskeid tussen die twee nature nie 
opgehef word deur hulle vereniging nie, maar elkeen bly sy eie aard behou, maar aan die ander kant ook vashou aan 'n ander uitspraak van dieselfde belydenis dat die twee nature in één persoon verenig is, sodat Christus nie in twee persone verdeel of geskei kan word nie, aangesien daar maar één Seun van God is, die eniggebore God en Logos, die Here Jesus.

In die lig van die voorafgaande studie en gevolgtrekkings, is dit ons oortuiging dat ' $n$ mens wel nie die leer van die an- en enhupostasie kan gebruik om die tweede gebod ook op Christus na sy mensheid van toepassing te maak en so sonder voorbehoud enige afbeelding van Christus te verbied nie. Inteendeel, indien daar erns gemaak word met die ware mensheid van Christus soos dit o.a. in die Nederlandse Geloofsbelydenis artikel 18 gestel word, sal ons die moontlikheid van afbeeldinge van Christus moet toegee. ' $n$ Mens kan wel afbeeldinge van Christus maak, maar dadelik moet ook gesê word dat dit nie ongekwalifiseerd gedoen kan word nie. Afbeeldinge van Christus mag myns insiens nie op oppervlakkige wyse gedoen of gebruik word nie. Christus mag in afbeeldinge nie as 'n soort prentverhaal- of inkleurboekkarakter benader word nie. Die rede hiervoor is onder andere dat ons wel rekening moet hou met die gevare verbonde aan afbeeldinge soos gestel in punte 3, 4 en 6 van die argumente teen afbeeldinge van Christus aan die begin van hierdie artikel. Die vernaamste rede is egter dat hoewel ons Christus altyd as egte en ware mens kan benader, ons Hom nooit as net alleen nog 'n gewone mens kan benader nie. Ons moet Hom altyd benader met die eerbied vir die Goddelike geheimenis van sy Persoon. Hierdie selfde eerbied moet ook na vore kom in ons gebruik van afbeeldinge van Christus. Ons moet altyd laat deurskemer dat ons wel daarmee rekening hou dat daar êrens agter die Jesus wat ons na sy mensheid afbeeld tegelyk ook sy Godheid verskuil vir ons menslike oë lê. Dit is ook iets wat in die afbeeldinge en skilderye wat groot kunstenaars deur die eeue heen van Christus gemaak het na vore kom, en wat hulle werk juis so groot en aangrypend maak. 'n Ware groot kunstenaar probeer altyd iets weergee van die persoonlikheid en karakter van die persoon wat hulle skilder. Daarom sien ons in die voorstellings van groot kunstenaars altyd iets van hulle worsteling om ook uitdrukking te gee aan hulle eerbiedige besef dat hulle ook te doen het met hulle Verlosser, Heer en God, al probeer hulle hom net as mens in sy omwandeling op aarde voorstel. Hierdie worsteling van die kunstenaar is mooi verwoord in die volgende 
aanhaling: "In representing the person of Christ, this profound consideration of the interaction of manner and meaning is the more essential in that $\mathrm{He}$ is the great Paradox. In this one being the apparant oppositions of Human and Divine nature meet and are reconciled. Christ Crucified is the symbol of the triumph of Resurrection and Majesty. Compassion and humility contrast with power and glory. The carpenter, teacher and the shepherd of men is also the King, the Creator, the Lord Almighty; God is contained in human form. No single representation or image can possibly convey all the aspects; putting a cruciform halo around the head of an idealized human figure is nog an adequate response. Obviously it is not possible to create a compelling image without inner depths of thinking and feeling. These need not be expressed in orthodox phrases, or even in words at all. For most artists the meaning will emerge in the image he makes and not in comments about it" (1,p 56-58).

Behalwe die eerbied vir die geheimenis van Christus se Persoon moet ons in ons afbeeldinge van Christus ook steeds bewus bly van die beperktheid van ons menslike vermoë om ' $n$ oortuigende beeld van Christus weer te gee. 'n Opmerking ter syde is hier ter wille van die interessantheid geoorloof: Dit is opmerklik hoe kunstenaars se beeld van Christus in hulle voorstellinge van Hom gevorm is deur dinge soos die geldende opvatting van kuns, die kleredrag, sosiale lewe, mensbeeld, ens. van hulle betrokke tyd (1,p $60 \mathrm{ff})$.

In die lig van bogenoemde opmerkings is dit wat afbeeldinge van Christus in die sg. "kinderbybels" betref, as 'n mens die afbeeldinge dan daarin wil plaas, verkieslik om 'n hele reeks verbeeldinglose illustrasies heeltemal te vermy, want so loop ons gevaar om die nodige eerbied vir die Persoon van Christus verlore te laat gaan. Dit is beter om ' $n$ mens te beperk tot enkele illustrasies waarin daar probeer word om ook iets van die piëteit en eerbied vir die Persoon van Christus te laat deurskemer. As daar nie met 'n kunstenaar van hoogstaande formaat gewerk word nie (wat gewoonlik die geval is) kan die doelwit van eerbied makliker bereik word met 'n meer impressionistiese styl of 'n styl van sketsmatige lyne. In dié verband het ek persoonlik ook aanvoeling vir die uitgangspunt van die mense wat dit vermy om Christus se gesig van voor uit te beeld.

Laastens: Kan ons ons losmaak van reformatoriese erfenis met die klem op verkondiging deur die Woord alleen en onvoorwaardelik afbeeldinge van Christus goedkeur? Dit is te betwyfel. Daarom behoort dit steeds 'n saak te bly wat omsigtig en voorwaardelik be- 
nader word en behoort 'n mens steeds respek te hê vir die standpunt van die mense wat vanuit hulle eerbied vir die Goddelike natuur in die Persoon van Christus, afbeeldinge van Christus afwys.

Literatuurlys:

1. CHILD, HEATHER and COLLES, DOROTHY 1979'. Christian Symbols. Ancient and modern. A handbook for students. London: Bell and Hyman.

2. DUVENHAGE, SCW 30 Okt. 1963. Afbeeldinge van Christus in die Kerkblad p 9-11.

3. ENGELBRECHT, BJ Aug 1983. Passiespel: wyse van verkondiging ongeoorloof in Die Hervormer se Vrouehervormer-afdeling $p 1$ en 3.

4. HATTJEMA, Th L 1962. De Heidelbergse Catechismus als klankbodem en inhoud van het actuele belijden onzer kerk Wageningen: $H$ Veenman en Zonen N.V.

5. HERVORMER, die Julie 1983. Die Algemene Kerkvergadering in oënskou in die Vrouehervormer-afdeling $\mathrm{p} 1$ en 3.

6. JONKER, WD 1977. Christus die Middelaar. Wegwysers in die dogmatiek deel 2 Pretoria: NG Kerkboekhandel.

7. MARAIS, W 1978. Die tien woorde van God. Pretoria: NG Kerkboekhandel.

8. OTT, H 19732. Die Antwort des Glaubens. Systematische Theologie in 50 Artikeln. Stuttgart: Kreuz Verlag.

9. RÖDDING, G 1974. Dogmatik im Grundrisz. Gütersloh: Gütersloher Verlaghaus Gerd Mohn.

10. SCHOLTEMEIJER, H 13 Nov. 1963. Afbeeldings van Christus en die sonde teen die tweede gebod, in die Kerkblad p 7-9.

11. SCHULZE, LF 1978. Geloof deur die eeue. Pretoria: NG Kerkboekhandel.

12. VAN WYK, JA 1968. Etiek. Bloemfontein: NG Sendinguitgewers.

13. WEBER, O 1962. Grundlagen der Dogmatik Zweiter Band. Neukirchen - Moers: Neukirchener Verlag. 